\title{
DESIGN AND OPTIMIZATION OF INTEGRATED BLUETOOTH AND UWB ANTENNA WiTH DUAL BAND-NOTCHED FUNCTIONS
}

\author{
Su Sandar Thwin ${ }^{1}$ \\ ${ }^{1}$ Faculty of Engineering, Multimedia University, Cyberjaya 63100, Selangor, Malaysia \\ su. sandar@mmu. edu.my
}

\begin{abstract}
A compact microstrip-fed printed planar integrated Bluetooth and ultra wideband (UWB) monopole antenna with dual band-notched characteristics in the $3.5 \mathrm{GHz}$ WiMAX and 5.2/5.8GHz WLAN band is presented. The proposed antenna design consists of the semicircular ring patch and partial ground plane. The extra band (2.33-2.5GHz)for Bluetooth is obtained by adding the T-shaped strip at the top of the patch. Additionally, two L-shaped arc slots in patch and two U-shaped circular slots in partial ground plane are etched to reject the WiMAX and WLAN bands. The numerical and experimental results show that the proposed antenna has an impedance bandwidth of VSWR $\leq 2$ from $2.33 \mathrm{GHz}$ to $2.5 \mathrm{GHz}$ for Bluetooth band and $3.04 \mathrm{GHz}$ to $10.8 \mathrm{GHz}$ for $\mathrm{UWB}$ band except the notch band frequencies $3.3-4.1 \mathrm{GHz}$ for WiMAX and 5 - $5.9 \mathrm{GHz}$ for WLAN band.
\end{abstract}

\section{KEYWORDS}

Bluetooth antenna, Dual band-notched characteristics, UWB antenna

\section{INTRODUCTION}

UWB communication systems have attracted great attention in the wireless world because of their advantages, including high speed data rate, extremely low spectral power density, high precision, low cost and low complexity. The Federal Communication Commission (FCC) allowed the 3.1-10.6 GHz unlicensed band for UWB communication in February 2002[1]. Since then, many researchers have focused on the UWB technology and UWB antenna designs. However, this frequency band will cause interference with IEEE 802.16 (3.3-3.8GHz) Worldwide Interoperability for Microwave access (WiMAX) and IEEE 802.11a(5.15-5.85GHz) Wireless Local Area Network(WLAN). Therefore, the UWB antenna with band rejection characteristics is required to avoid possible interference between UWB and narrow bands like WiMAX and WLAN. Several types of monopole antennas have been proposed for UWB and band-notched applications [2-8]. A recently reported antenna has been designed by etching a rectangle slot in the CPW ground [2], by embedding a parasitic strip inside the polygon slot and an isolated slit employed in the bevelled T-stub [3], and use the two L-shaped quarterwaveguide resonators coupled to the ground plane with two shorting tracks at the sides of the antenna [8] to get the single band-notched characteristic. In [4], the dual notched bands were formed by embedding a pair of $\Gamma$-shaped stubs in the radiation patch and a modified G-slot defected ground structure in the feeding line. Nowadays, the Bluetooth covering the 2.4-2.484 $\mathrm{GHz}$ band is widely used in portable devices and essential to integrate multiple bands for use in one device. The integrated Bluetooth and UWB antenna with band-notched characteristics are 
proposed in [9-12]. In [9], the antenna structure consists of a microstrip-fed main patch and electromagnetically couple parasitic patch with arc-shaped strips for achieving Bluetooth and UWB performance and the split ring resonator (SRR) slot etched on the main patch and the square patch close to microstrip feed line are aimed to obtain dual notched bands.

This paper proposes a compact microstrip-fed printed planar monopole antenna that covers both the Bluetooth and UWB band with WiMAX and WLAB band-notched. T-shaped strip is added at the top of the semicircular ring patch for Bluetooth and UWB performances. The two Lshaped arc slots in main patch and two U-shaped circular slots in partial ground plane are etched to reject the WiMAX and WLAN bands. Details of the proposed antenna design, simulated and measured results are discussed below.

\section{Antenna Design}

\subsection{Geometry of the Antenna}

The geometry of the proposed Bluetooth and UWB antenna with dual notched bands is illustrated in Figure 1, with its geometry parameters. The proposed antenna is fabricated on a FR4 substrate with relative permittivity of 4.4 , thickness of $1.6 \mathrm{~mm}$ and a loss tangent of 0.02 . The dimension of this antenna is $30 \times 41 \mathrm{~mm}^{2}$. The antenna provides the extra Bluetooth band operation due to the T-shaped strip added on the radiation patch. The T-shaped strip creates a notched band to prevent interference between the Bluetooth and UWB band. Two symmetrical L-shaped slot is etched in the radiation patch and two symmetrical U-shaped circular slot is etched in the ground plane to prevent the interference of WiMAX and WLAN band.
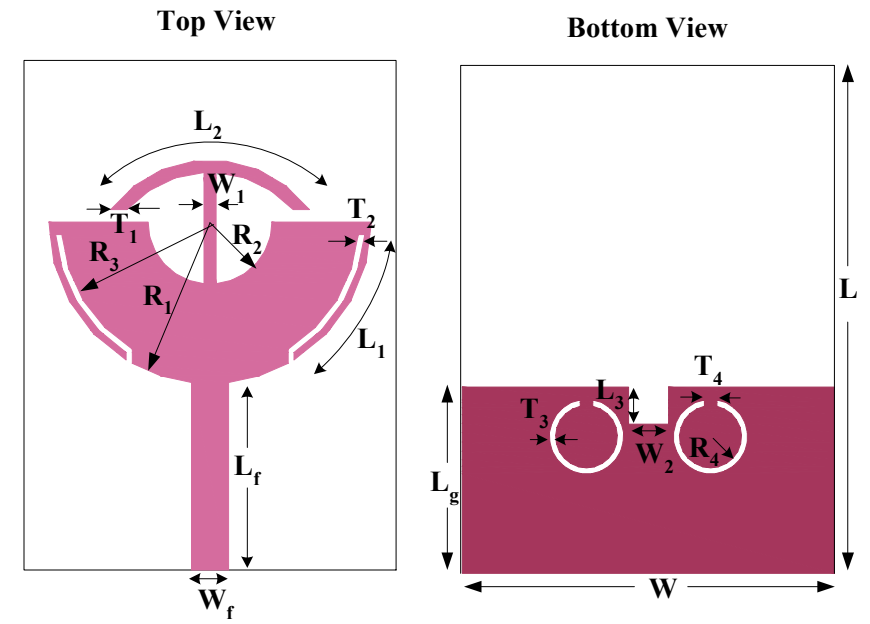

Figure 1: The geometry and parameters of proposed antenna

\subsection{Parametric Study}

The simulation tool Ansoft High Frequency Structure Simulator (HFSS) is used for performing the design and optimization process. In the optimization process, some parameters like T-strip, $\mathrm{L}$-slot and U-slot are the main factors for extra resonant mode and notch bands. The lengths of T-strip $\left(\mathrm{L}_{2}\right)$, L-slot $\left(\mathrm{L}_{1}\right)$, the width of L-slot $\left(\mathrm{T}_{2}\right)$ and the gap of U-slot $\left(\mathrm{T}_{4}\right)$ are selected in the parametric study and study one parameter at a time and others are fixed to get better understanding for these parameters. 


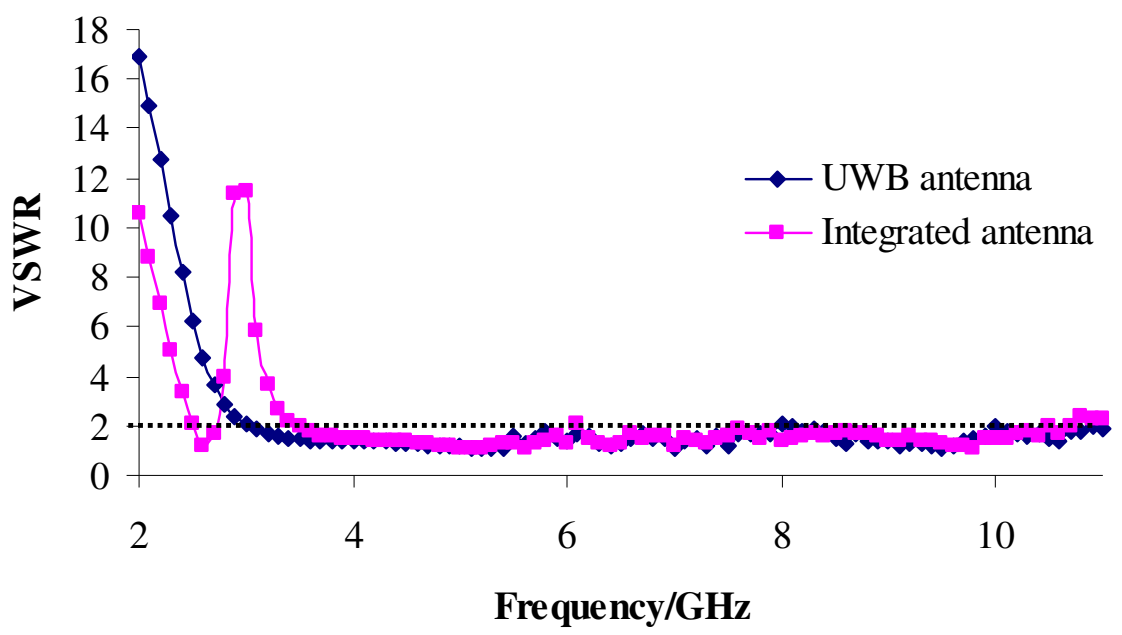

Figure 2: Simulated VSWR characteristics of the UWB antenna and Integrated Bluetooth/UWB antenna

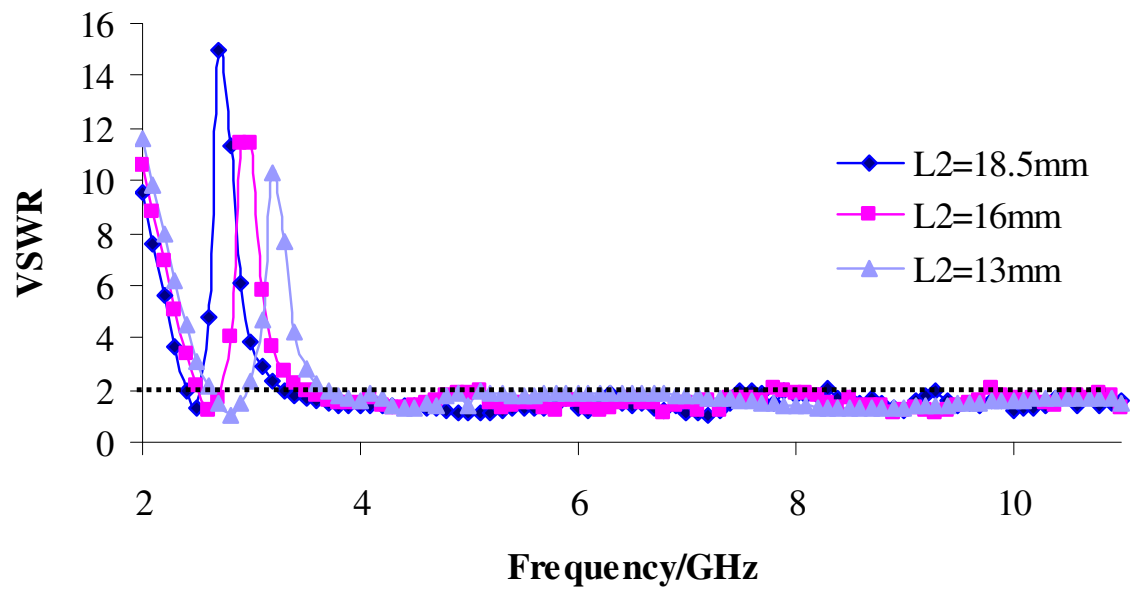

Figure 3: Simulated VSWR characteristics of the antenna with different value of $\mathrm{L}_{2}$

First of all, the primitive antenna and $50 \Omega$ microstrip feed line are calculated according to the substrate's relative permittivity and thickness. The T-shaped strip is added on the radiation patch to get extra resonant frequency of $2.4 \mathrm{GHz}$ Bluetooth. The length of the strip and slot can be approximated by

$$
\begin{aligned}
& L_{\text {notch }}=\frac{c}{4 f_{\text {notch }} \sqrt{\varepsilon_{e f f}}} \\
& \varepsilon_{\text {eff }} \approx \frac{\left(\varepsilon_{r}+1\right)}{2}
\end{aligned}
$$

where $\varepsilon_{\text {eff }}$ is the approximate effective dielectric constant and $f_{\text {notch }}$ is the center frequency of notch band, $\mathrm{c}$ is the speed of light. The simulated VSWR characteristics of the primitive UWB antenna and integrated Bluetooth and UWB antenna are illustrated in Figure 2. 


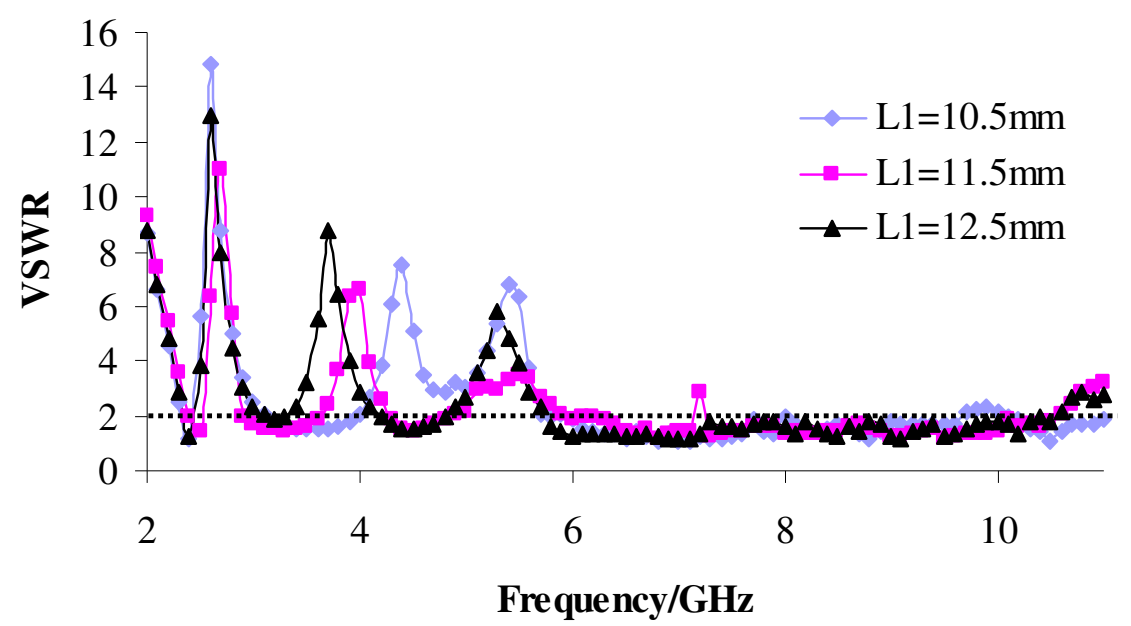

Figure 4: Simulated VSWR characteristics of the proposed antenna with different value of $\mathrm{L}_{1}$

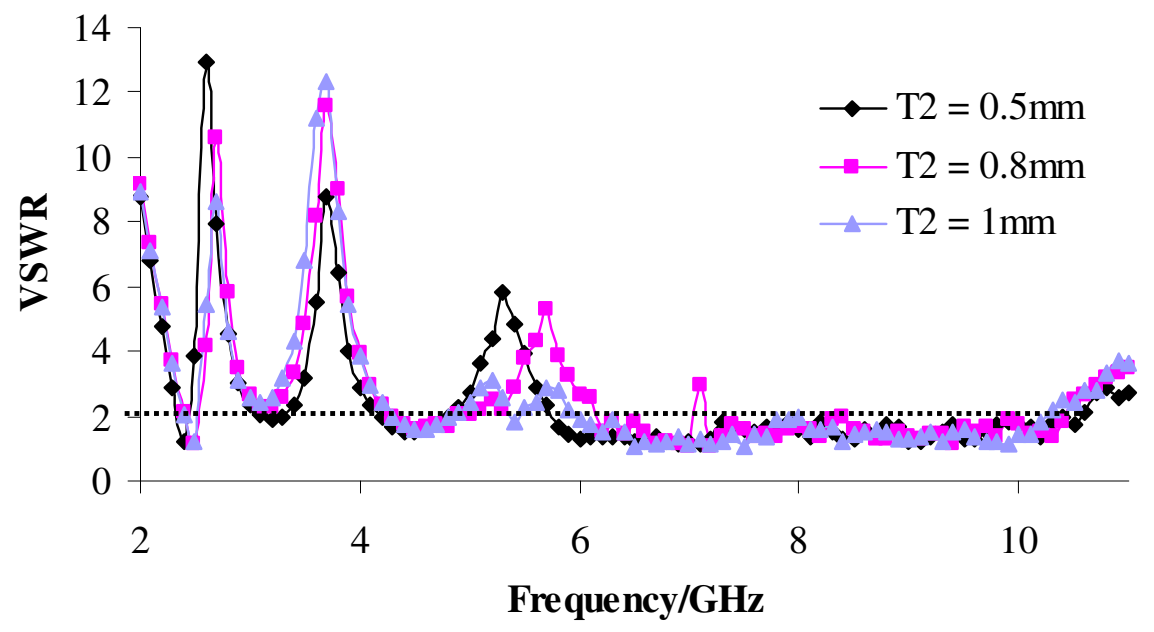

Figure 5: Simulated VSWR characteristics of the proposed antenna with different value of $\mathrm{T}_{2}$

Figure 3 shows the simulated VSWR characteristics of the integrated Bluetooth and UWB antenna without band notches for the different values of $L_{2}$. The T-shaped strip creates a notched band and an extra Bluetooth pass band simultaneously. It can be seen that the value of $\mathrm{L}_{2}$ effect obviously to the frequency of notch band and extra Bluetooth pass band. With the increasing of the $\mathrm{L}_{2}$, the notch frequency is decreasing and the VSWR of the notch band increasing. At the same time, additional Bluetooth frequency is appeared.

Figure 4 shows the simulated VSWR characteristics of the antenna as the function of frequency for the different values of $\mathrm{L}_{1}$ with other parameters are fixed. It can be seen that the value of $\mathrm{L}_{1}$ is not affected to the first and third band notch frequencies. To get the desired 3.5GHz WiMAX notch band, the length of L-shaped slot is adjusted. The notch frequency is decreasing when the increasing of $\mathrm{L}_{1}$. Similar for the 5.2/5.8GHz WLAN notch band, the length of the circular Ushaped slot (varying the values of $\mathrm{T}_{4}$ with fixed $\mathrm{R}_{4}$ ) is adjusted. The 5.2/5.8GHz WLAN notch band is decreasing when the increasing of circular slot length. 
International Journal of Computer Networks \& Communications (IJCNC) Vol.4, No.4, July 2012

The width of L- shaped slot is also affected to the bandwidth of the second notch band. The simulated VSWR characteristics curves with various values of $\mathrm{T}_{2}$ are illustrated in Figure 5. With the increasing of the width of the L-shaped slots, the bandwidth of the second notch band is getting wide and move to lower frequency edge.

\section{RESUlTS AND DiscuSSIONS}

After the parametric study of several adjustments on parameters, the final proposed antenna is achieved. The design parameters of the proposed antenna are given in Table 1.

Table 1: Parameters of the proposed antenna

\begin{tabular}{|c|c|c|c|c|c|c|c|c|c|}
\hline Parameter & $\mathrm{L}$ & $\mathrm{W}$ & $\mathrm{R}_{1}$ & $\mathrm{R}_{2}$ & $\mathrm{R}_{3}$ & $\mathrm{R}_{4}$ & $W_{f}$ & $\mathrm{~W}_{1}$ & $\mathrm{~W}_{2}$ \\
\hline Value(mm) & 41 & 30 & 13 & 5 & 12 & 2.5 & 3 & 1 & 3.2 \\
\hline Parameter & $\mathrm{L}_{\mathrm{f}}$ & $\mathrm{L}_{\mathrm{g}}$ & $\mathrm{L}_{1}$ & $\mathrm{~L}_{2}$ & $\mathrm{~T}_{1}$ & $\mathrm{~T}_{2}$ & $\mathrm{~T}_{3}$ & $\mathrm{~T}_{4}$ & \\
\hline Value(mm) & 15.5 & 15 & 12.5 & 18.5 & 1 & 0.5 & 0.5 & 1 & \\
\hline
\end{tabular}

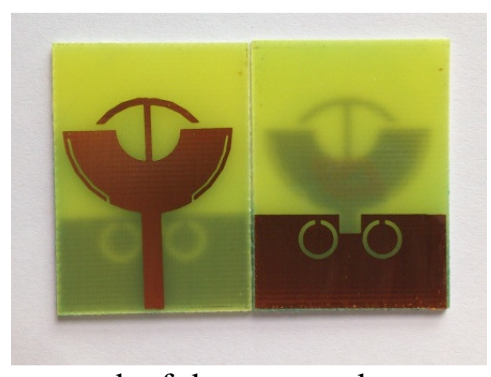

Figure 6: Photograph of the proposed antenna

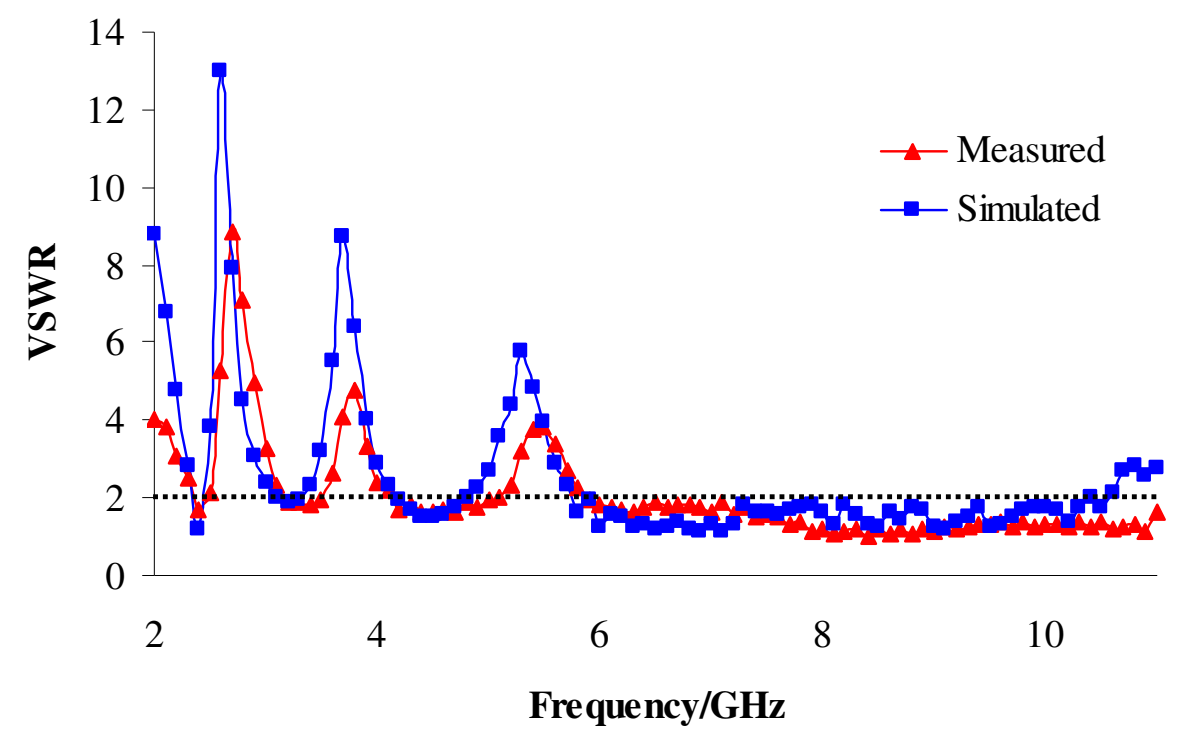

Figure 7: Measured and simulated VSWR characteristics of the proposed antenna 
International Journal of Computer Networks \& Communications (IJCNC) Vol.4, No.4, July 2012

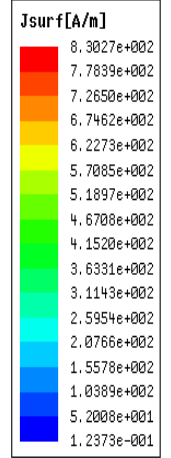

(a)

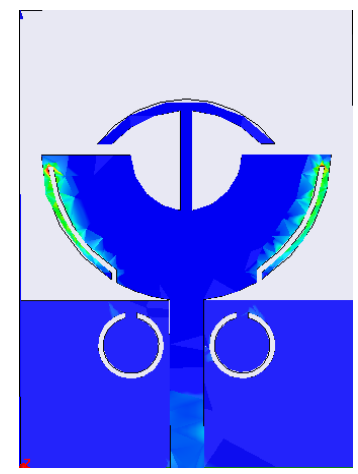

(b)

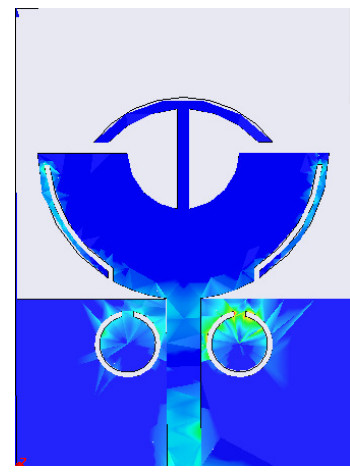

(c)

Figure 8: Surface current distributions of the proposed antenna at different frequencies.

(a) $2.8 \mathrm{GHz}$; (b) $3.5 \mathrm{GHz}$; (c) $5.5 \mathrm{GHz}$

In order to evaluate the performance of the optimized proposed antenna, a prototype of the proposed antenna was implemented and fabricated. The photograph of the fabricated antenna is shown in Figure 6. The VSWR was measured by Agilent 8722ES Vector Network Analyzer. Figure 7 shows the measured and simulated VSWR characteristics of the proposed antenna. The simulated bandwidth is $2.33-2.48 \mathrm{GHz}$ and $3.04-10.8 \mathrm{GHz}$ except $3.3-4.1 \mathrm{GHz}$ and $5-5.8 \mathrm{GHz}$ notched bands and the measured bandwidth is $2.33-2.5 \mathrm{GHz}$ and $3.15-11 \mathrm{GHz}$ except for 3.5 $4.1 \mathrm{GHz}$ and $5.1-5.9 \mathrm{GHz}$ notched bands. The simulated notched band's centre frequency between the Bluetooth and UWB is $2.6 \mathrm{GHz}$ and maximum VSWR value is 12.96. The measured notched band's centre frequency between the Bluetooth and UWB is $2.7 \mathrm{GHz}$ and maximum VSWR value is 7.93. The simulated VSWR values of WiMAX and WLAN bands are 8.75 at $3.7 \mathrm{GHz}$ and 5.79 at $5.3 \mathrm{GHz}$ and the measured VSWR values are 4.79 at $3.8 \mathrm{GHz}$ and 3.96 at $5.5 \mathrm{GHz}$. The WLAN band notch is shifted a little due to the fabrication accuracy and SMA connector to transmission line, which is not taken into account in the simulation results.

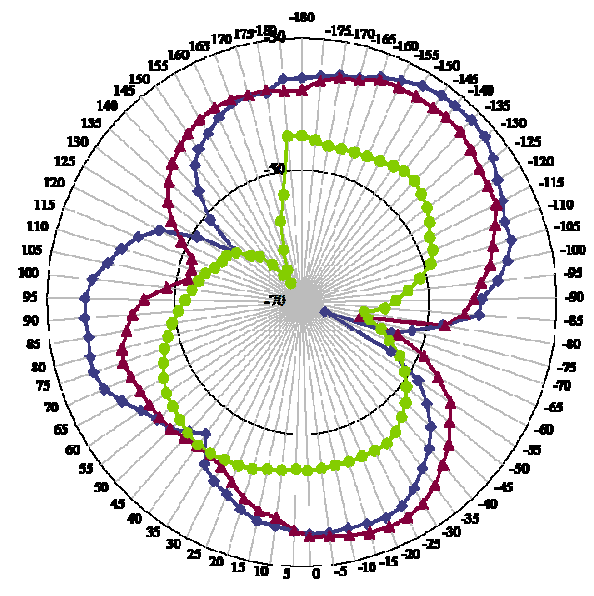

(a)E-plane $[\stackrel{+}{\longrightarrow} 2.4 \mathrm{GHz} ; \multimap 3.3 \mathrm{GHz}$

Figure 9: Measured radiation patterns of the proposed antenna

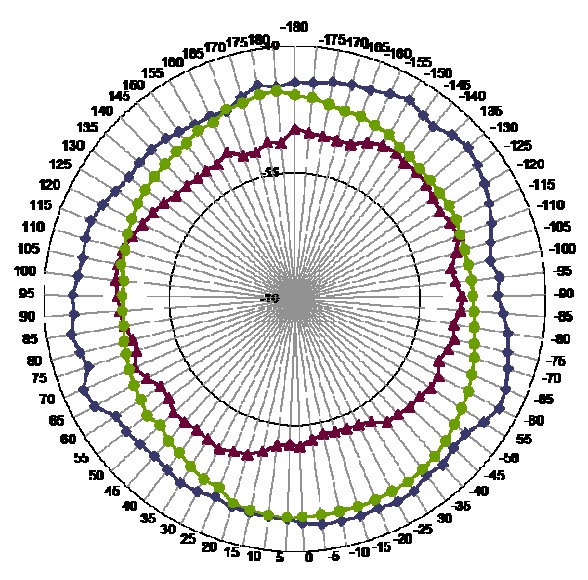

(b) H-plane $6.5 \mathrm{GHz}$ ] 
Surface current distributions of the proposed antenna at $2.8,3.5$ and $5.5 \mathrm{GHz}$ are studied for better understanding of the proposed antenna and are illustrated in Figure 8. The current distribution is highest along the T-shaped strip at $2.8 \mathrm{GHz}$. Similarly, the drastically increased current distributions around L-shaped slot and U-shaped slot at $3.5 \mathrm{GHz}$ and $5.5 \mathrm{GHz}$ which indicate that the slots and slits introduce the band notched functions at the respective frequencies.

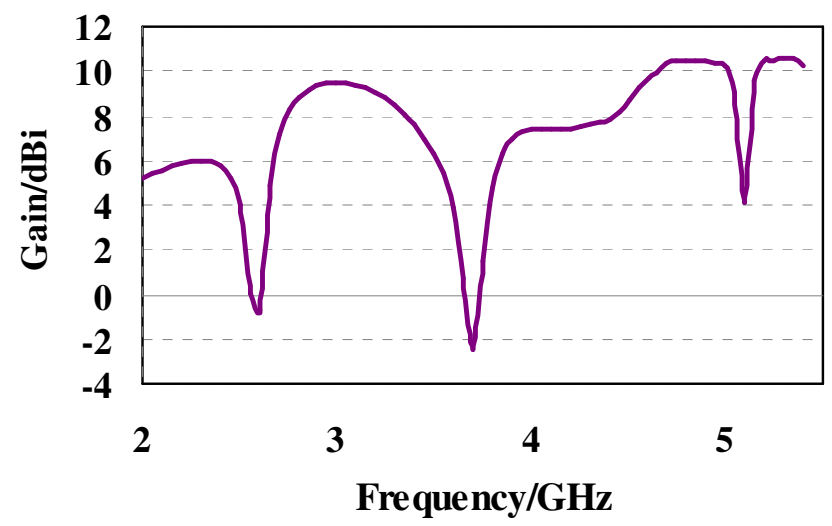

Figure 10: The peak gain of the proposed antenna

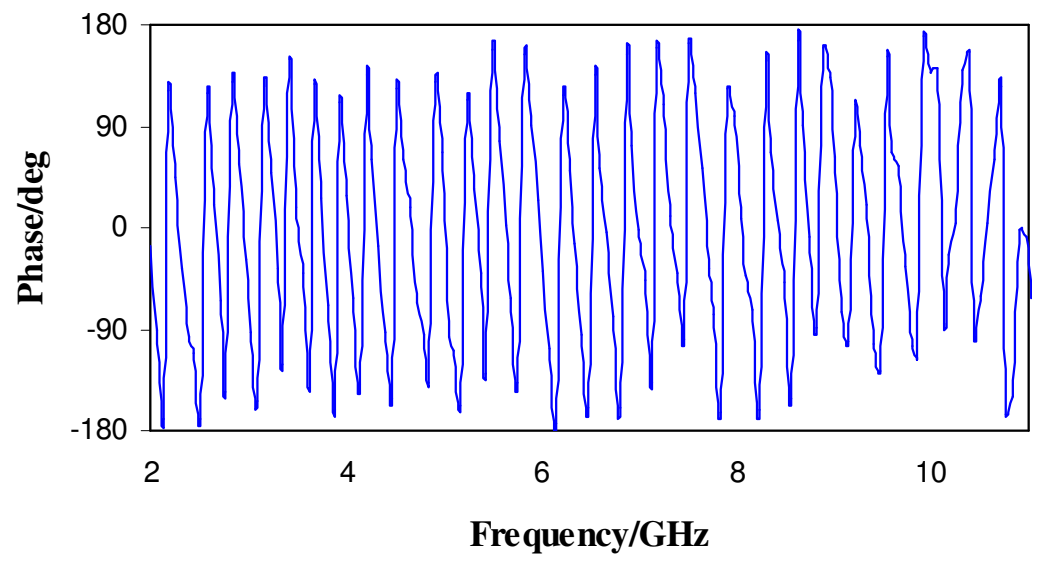

Figure 11: Phase response of the proposed antenna

The measured radiation patterns at $2.4 \mathrm{GHz}, 3.3 \mathrm{GHz}$ and $6.5 \mathrm{GHz}$ are shown in Figure 9. It can be seen that measured E-plane radiation pattern is a bidirectional as a traditional monopole antenna and $\mathrm{H}$-plane radiation pattern is nearly omnidirectional. The peak gain of the antenna from 2- $5.5 \mathrm{GHz}$ is shown in Figure 10. The gain of the proposed antenna decrease sharply at the notched bands of 2.6, 3.7 and 5.1GHz. The phase of the radiated field is illustrated in Figure 11, measured by an Agilent 8722ES vector network analyzer. The group delay is measured by placing the two identical antennas in face to face with a distance of $30 \mathrm{~cm}$ to evaluate the dispersion performance of the proposed antenna. The measured group delay is illustrated in Figure 12. The variation of group delay is within $2 \mathrm{~ns}$ apart from the notched bands. 
International Journal of Computer Networks \& Communications (IJCNC) Vol.4, No.4, July 2012

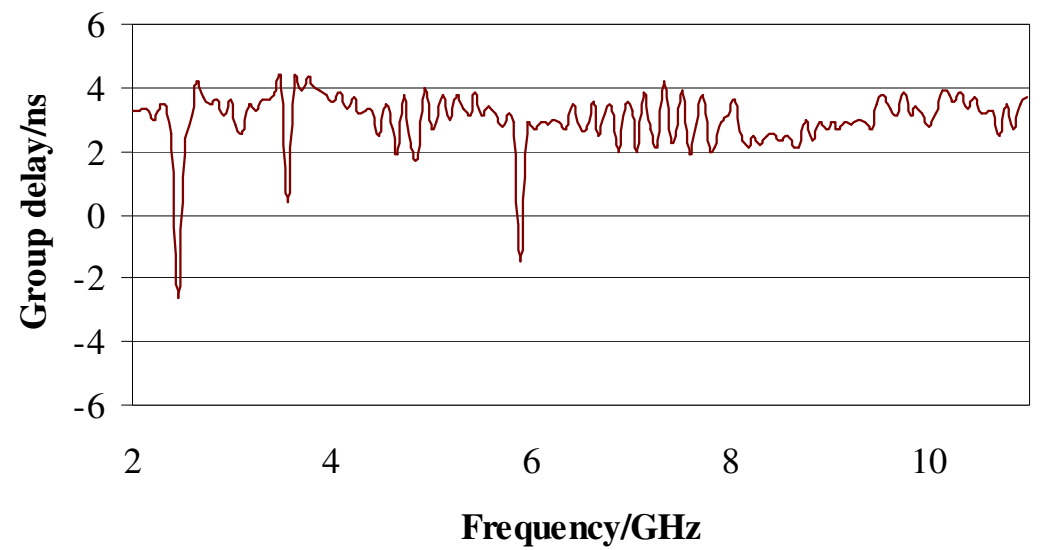

Figure 12: Group delay of the proposed antenna

\section{Conclusions}

A compact printed planar integrated Bluetooth and ultra-wideband antenna with dual band notched characteristics is presented. The proposed antenna has been simulated, fabricated and tested. To mitigate the potential interference between UWB system and narrowband systems such as WiMAX and WLAN, the L-shaped arc slot and U-shaped circular slot are etched on the current routes of patch and ground plane. The T-shaped slit not only produces the Bluetooth band but also notches the unnecessary band between the Bluetooth and UWB bands. It is observed that the radiation patterns are nearly omni-directional across the Bluetooth and UWB band. The group delay is within $2 \mathrm{~ns}$ in the working band, which shows that the proposed antenna is suitable for Bluetooth and UWB applications.

\section{REFERENCES}

[1] First report and order,(2002) “ Revision of Part 15 of the commission's rule regarding ultrawideband transmission system FCC02-48”, Federal Communications Commission .

[2] Y.-S. Li, X.-D. Yang, Q. Yang, and C.-Y. Liu, (2011) "Compact coplanar waveguide fed ultra wideband antenna with a notch band characteristics", Int. J. of Electron. Commn., vol. 65, pp. 961966.

[3] L.-H. Ye, and Q.-X. Chu, (2009) "Improved band-notched UWB slot antenna", Electorn. Lett., vol.45, no. 25.

[4] M. Abdollahvand, G.Dadashzadeh, and D.Mostafa, (2010) "Compact dual band-notched printed monopole antenna for UWB application”, IEEE Antennas and Wireless Propag Lett., vol.9, pp. $1148-1151$.

[5] W. Ren, J.Y.deng, and K.S. Chen, (2007)“Compact PCB monopole antenna for UWB applications”, J.of Electromagn. Waves and Appl., vol.21, No.10, pp.1411-1420.

[6] H. Yoshioka, L. Yang, E. Tammam, and K. Yoshitomi, (2012) "A highly compact dual-band WLAN/UWB monopole antenna”, IEICE Electron. Express, vol. 9, no. 3, pp. 160-164. 
International Journal of Computer Networks \& Communications (IJCNC) Vol.4, No.4, July 2012

[7] B. Kasi, L. C. Ping, and C. K. Chakrabarty, (2011) "A compact microstrip antenna for ultra wideband applications”, European J. of Scientific Research, vol.67, no.1, pp. 45-51.

[8] H. J. Lak, C. Ghobadi, and J. Nourinia, (2011) "A novel ultra-wideband monopole antenna with band-stop characteristic", Wireless Engg. and Tech., vol.2, pp.235-239.

[9] F.-C. Ren, F.-S. Zhang, J.-H. Bao, Y.-C. Jiao, and L. Zhou,( 2011)“Printed Bluetooth and UWB antenna with dual band-notched functions", Progress In Electronmagnetics Research Letters, vol.26, pp. 39-48.

[10] L. Xiong and P. Gao, (2012) "Dual-band planar monopole antenna for Bluetooth and UWB applications with WiMAX and WLAN band-notched", Progress In Electromagnetic Research Letters, vol.28, pp. 183-194.

[11] A. Shaker, S. H. Zainud-Deen, K. R. Mahmoud, and S. M. Ibrahem, (2011) "Compact Bluetooth/UWB antenna with multi-band notched characteristics", J.of Electromagn. Anal. and Appl., vol.3, pp. 512-518.

[12] M. M. S. Taheri, H. R. Hassani, and S. M. A. Nezhad, (2011) "UWB printed slot antenna with Bluetooth and dual notch bands”, IEEE Antennas and Wireless Propag. Lett., vol.10, pp. 255-258. 